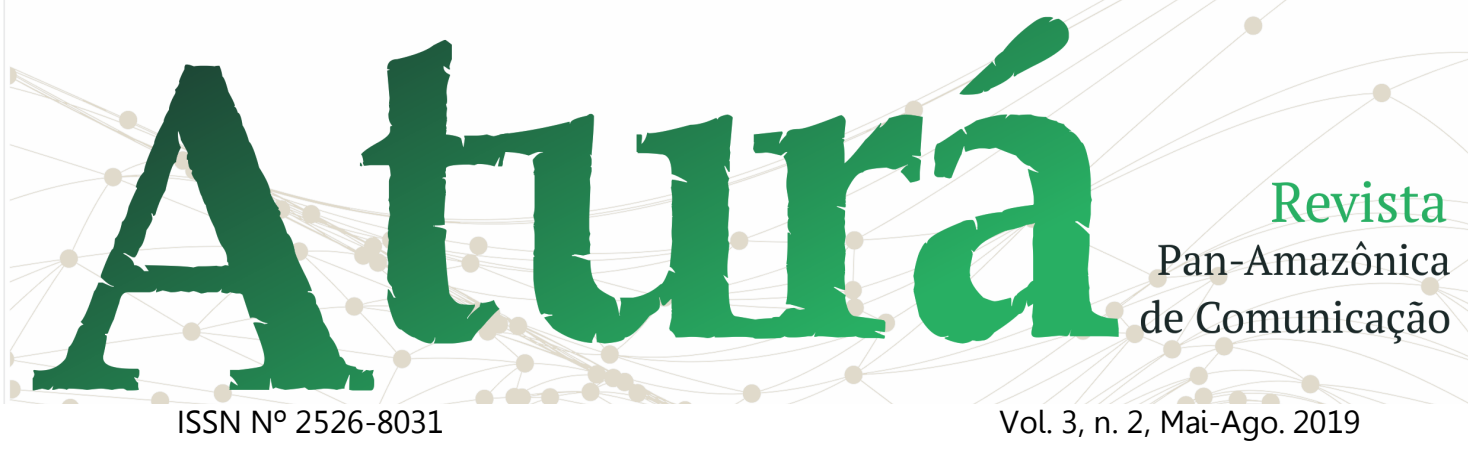

\title{
PRÁTICAS DOCENTES E TECNOLOGIAS DA COMUNICAÇÃO E DA INFORMAÇÃO: $O$ que dizem os docentes envolvidos em processos de formação
}

Teaching practices and Communication and Information Technologies: What do teachers involved in training processes say

Prácticas de enseñanza y tecnologías de la información y la comunicación: ¿qué dicen los docentes involucrados en los procesos de capacitación?

\section{Francisco Gilson Rebouças Porto Junior ${ }^{1}$}

\section{RESUMO}

A análise efetuada neste trabalho teve como objeto as práticas docentes desenvolvidas docentes em universidades portuguesas por ocasião da implementação do Processo de Bolonha. O foco foi entender como as práticas docentes envolvidas na formação em Comunicação Social/Jornalismo foram afetadas pelas tecnologias emergentes e pelo Processo Bolonha. A percepção dos a(u)tores é bem ampla sobre as estratégias de formação acadêmica antes e pós-Bolonha, amplificadas pelas tecnologias das duas últimas décadas.

PALAVRAS-CHAVE: Processo de Bolonha; Formação; União Europeia; Comunicação.

\section{ABSTRACT}

The analysis carried out in this work had as its object the teaching practices developed by teachers in Portuguese universities during the implementation of the Bologna Process. The

\footnotetext{
${ }^{1}$ Doutor em Comunicação e Cultura Contemporâneas pela Faculdade de Comunicação da Universidade Federal da Bahia (UFBA), mestre em Educação pela Faculdade de Educação (UnB) e graduado em Comunicação Social/Jornalismo (ULBRA) e Pedagogia (UnB). Atualmente é líder do Núcleo de Pesquisa e Extensão e Grupo Lattes Observatório de Pesquisas Aplicadas ao Jornalismo e ao Ensino (OPAJE-UFT). É professor na Fundaçãao Universidade Federal do Tocantins (UFT). E-mail: gilsonporto@uft.edu.br.
} 


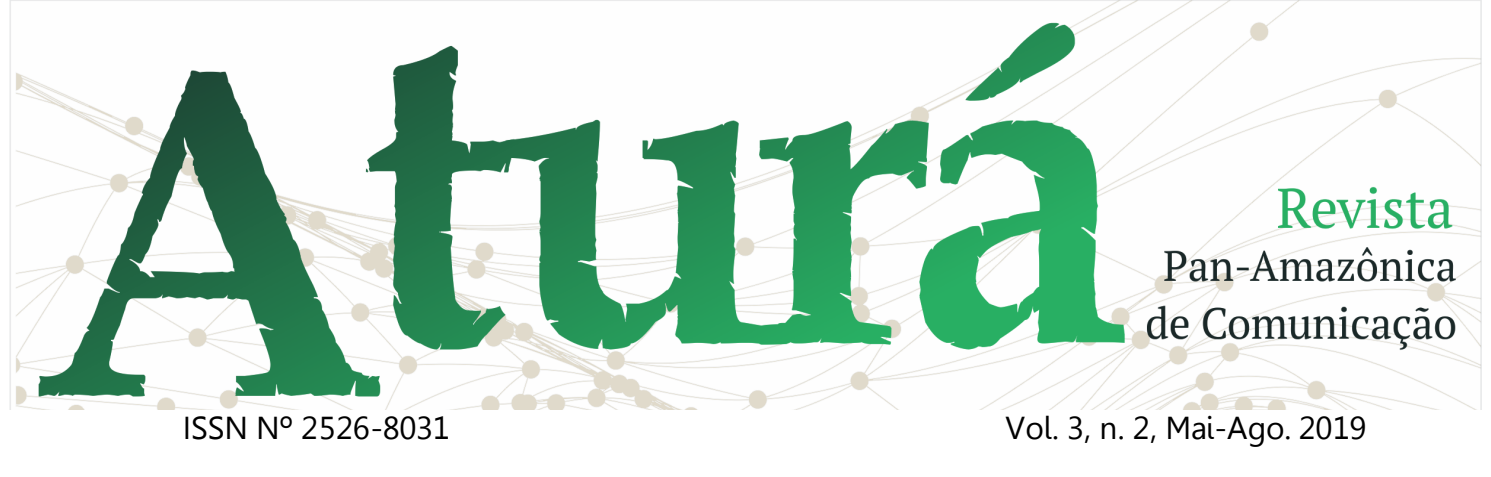

focus was to understand how the teaching practices involved in Social Communication / Journalism training were affected by emerging technologies and the Bologna Process. The perception of the authors is very wide about the strategies of pre and post-Bologna academic formation, amplified by the technologies of the last two decades.

KEYWORDS: Bologna Process; Formation; European Union; Communication.

\section{RESUMEN}

El análisis realizado en este documento tuvo como objeto las prácticas docentes desarrolladas por los docentes en las universidades portuguesas durante la implementación del Proceso de Bolonia. El objetivo era comprender cómo las prácticas docentes involucradas en la capacitación en Comunicación Social / Periodismo se vieron afectadas por las tecnologías emergentes y el Proceso de Bolonia. La percepción de los autores es muy amplia sobre las estrategias de formación académica pre y post Bolonia, amplificadas por las tecnologías de las últimas dos décadas.

PALABRAS CLAVE: Proceso de Bolonia; Entrenamiento; Unión Europea; Comunicación.

Recebido em: 24.02.2019. Aceito em: 24.04.2019. Publicado em: 01.05.2019. 


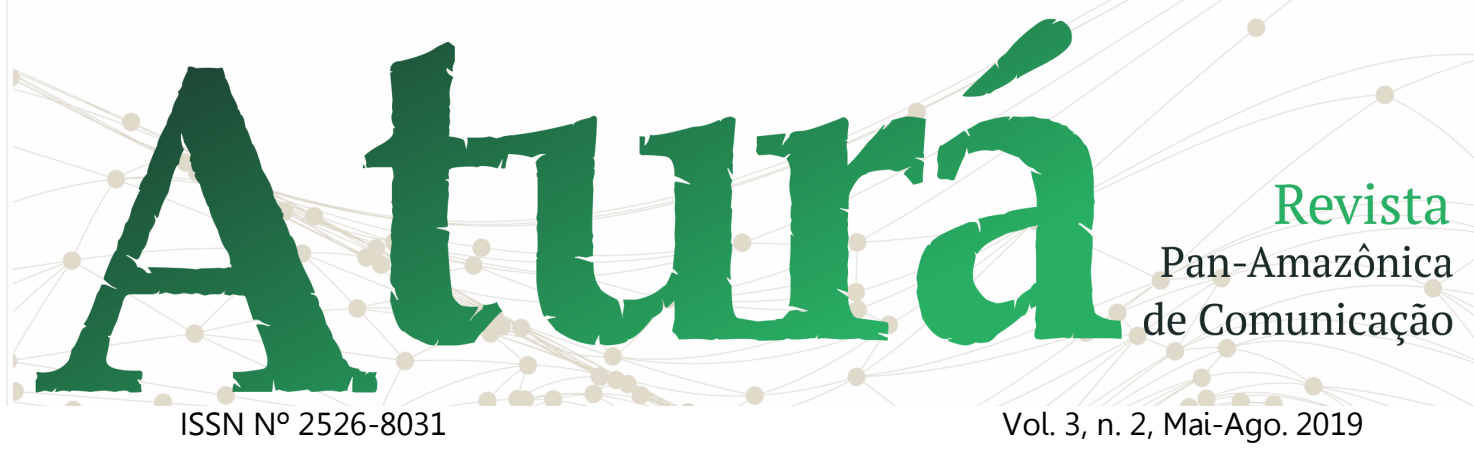

\section{Introdução}

A prática docente em qualquer área do conhecimento é sempre uma ação complexa. Por um lado, envolve seguir regramentos pedagógicos validados pelos pares, mas por outro, processos de autoria, criação e recriação do saber e do conhecimento (ALVES et al., 2017; BATISTA;MACIEL, 2018; MELO, 2017; MOIO; VIEIRA, 2017; MOTA; FERREIRA, 2017). Isso nem sempre é fácil de conciliar.

Agregue-se a isso, nas últimas décadas, a inclusão das tecnologias da comunicação e da Informação que trouxeram elementos novos, ressignificando práticas já consolidadas entre docentes e instituições (NUNES; PORTO JUNIOR; MORAES, 2017; PORTO JUNIOR; MORAES, 2017; PORTO JUNIOR, 2015; PINHO, 2017; REIS, 2017; TEIXEIRA, 2010; TEIXEIRA; SILVA; MARTINS, 2017).

Nesse artigo, se percorre a percepção de docentes responsáveis pela implantação de mudanças curriculares em certos momentos e como a transição e inclusão das tecnologias da comunicação e da informação foram elementos de crise, exigindo mudanças e repensar de práticas.

\section{DETALHAMENTO DO CORPUS E DOS PROCEDIMENTOS DE PESQUISA}

A pesquisa relatada neste artigo é de cunho qualitativo e interpretativo. A análise efetuada neste trabalho teve como objeto compreender os processos e a avaliação que professores-gestores fazem dos impactos de Bolonha nas competências formativas, quer na relação com as disciplinas, com outros docentes, quer com discentes e/ou universidades e até com o mercado de trabalho do egresso em Comunicação Social e Jornalismo. Foram quatro universidades portuguesas pesquisadas, a saber: Universidade da Beira Interior, Universidade do Minho, Universidade do Porto e a Universidade Fernando Pessoa (PÔRTO JÚNIOR, 2012). Selecionaram-se as universidades que possuíam turmas nos três ciclos (Licenciatura - $1^{\circ}$ ciclo, Mestrado - $2^{\circ}$ ciclo e Doutorado - $3^{\circ}$ ciclo) adequadas (ou em processo final) à Bolonha, expertise na implantação das mudanças e que fossem representativas dos modelos portugueses de gestão universitária (pública, mista e particular).

Cada instituição de ensino superior foi tratada sob a óptica de um estudo de caso para compreensão situacional. A opção pelo estudo de caso deu-se devido à contribuição desse método para a compreensão dos fenômenos individuais, grupais e organizacionais, sociais e 


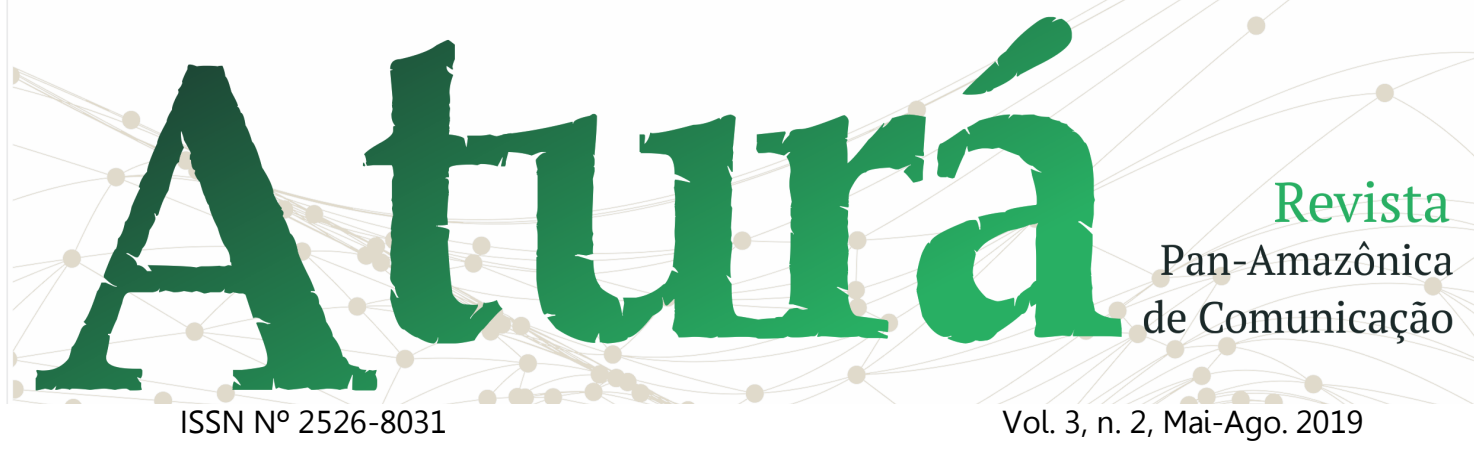

políticos (YIN, 2010; DUARTE, 2005a). Com isso em mente, optou-se, nesta pesquisa, mesmo tratando cada universidade como "um caso", com suas especificidades e seus momentos, tratálas de forma integrada e holística em suas características no momento de apresentar os resultados.

Decidiu-se por utilizar a entrevista semiaberta, com perguntas abertas, em que cada informante tinha liberdade de desenvolver suas ideias e percepções a partir de questões de norteamento (DUARTE, 2005b). Foram entrevistados, em cada instituição universitária, professores-gestores (coordenadores de cursos de graduação/licenciatura, coordenadores de programas de mestrado e doutorado, diretores de cursos/faculdades, PróReitores) que participaram ativamente nas diversas fases de implantação e implementação do Processo de Bolonha desde 1999 até 2012. Aplicou-se um instrumento de coleta de informações, percepções e experiências do informante, nomeado "roteiro de entrevista" que foi dividido em três blocos: Bloco 1 dinâmica de transformação das estratégias de formação acadêmica; Bloco 2 - processos formativos; e Bloco 3 impacto dos processos macro de ajustes educacionais/jurídicos. Os dois primeiros blocos foram constituídos de três perguntas cada e o último de duas perguntas. Os blocos foram separados propositadamente de acordo com os objetivos de pesquisa, visando a facilitar ao pesquisador 0 processo de organização e compreensão das diversas falas e percepções (MARTINS; THEÓPHILO, 2007; DUARTE, 2005b).

As hipóteses de pesquisa foram testadas na medida em que se realizaram as entrevistas e colheram-se as falas dos atores formadores, que são também, nesse processo, "autorescriadores" de novas práticas formativas. Daí a opção de entendê-los como "a(u)tores", já que, mesmo sendo "criadores" de um novo fazer formativopedagógico, alguns não se compreendiam plenamente nesse papel.

A percepção dos a(u)tores sobre esse movimento ajuda a vislumbrar elementos constitutivos dos processos envolvidos nas mudanças curriculares. Optou-se por apresentar a fala ${ }^{2}$ dos sujeitos "a(u)tores" sobre cada tema entrecruzado das referidas análises. Com isso, procura-se compreender como a "[...] realidade [...] revela tudo que os afasta" das mudanças formativas essenciais no âmbito de Bolonha (WOLTON, 2004, p.

\footnotetext{
2 Optou-se por manter as falas dos autores no português com as variantes existentes em Portugal. Dessa forma, algumas construções não seguem a norma gramatical praticada atualmente, além de conter os próprios vícios de linguagem dos entrevistados. Interpolações são incluídas para dar sentido a algumas palavras. Elas são marcadas com colchetes ([]).
} 


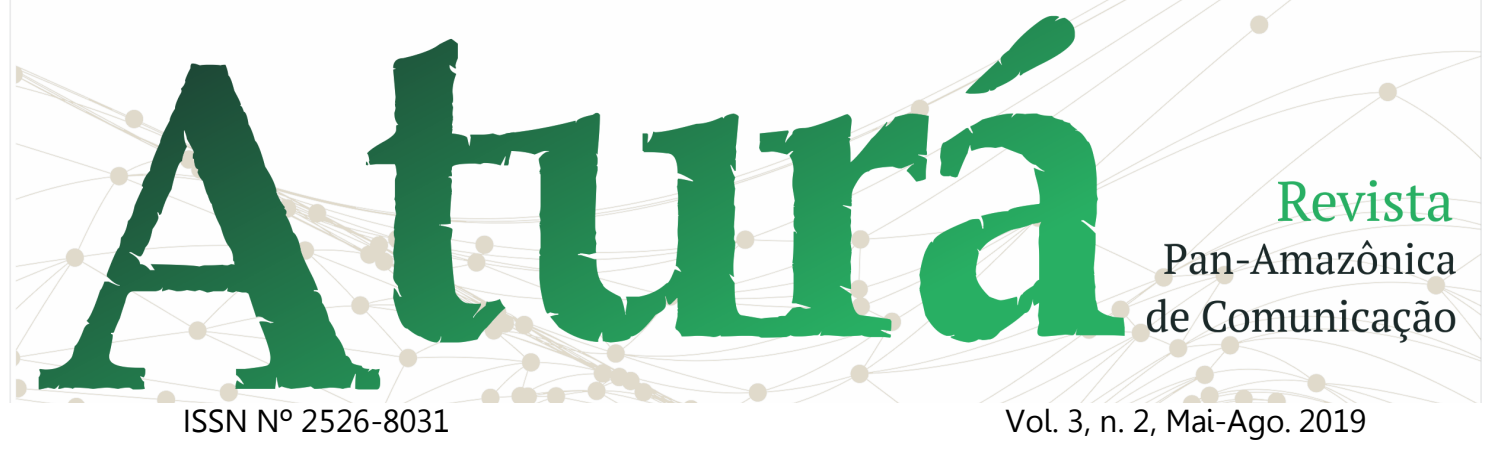

37). Longe de objetivarem a exaustão, tais falas são indicativas de possibilidades que permearam as percepções dos entrevistados, servindo de exemplificações dos questionamentos ora apresentados. Para tanto, resguarda-se a identidade dessas universidades, apontando cada uma delas com as letras "A" a "D", e os a(u)tores por números, optando-se por manter a titulação e indicação de atividades desenvolvidas durante o processo de implantação de Bolonha.

\section{RESULTADOS E DISCUSSÃO}

Indagou-se aos a(u)tores sobre as práticas docentes desenvolvidas. $O$ foco foi entender como as práticas docentes envolvidas na formação em Comunicação Social/Jornalismo foram afetadas pelas tecnologias emergentes e pelo Processo Bolonha. A percepção dos a(u)tores é bem ampla sobre as estratégias de formação acadêmica antes e pósBolonha, amplificadas pelas tecnologias das duas últimas décadas.

Para a prof. ${ }^{a}$ Dra. A, na Universidade $A$, as transformações foram positivas, pois "[...] penso que isso tornou as aulas mais dinâmicas, digamos assim, na questão de se começarem a utilizar em massa argumentos audiovisuais para cativar os alunos [...]. Quando dava aula com apontamentos tradicionais, ficava difícil recortar, montar e transportar. A informatização disso faz com que seja muito fácil montar blocos, seminários, montar o programa de uma cadeira, e isso é uma ferramenta de produtividade $\mathrm{p}[\mathrm{a}] \mathrm{ra}$ nós enquanto docente[s]. O que eu noto é que os professores vão aderindo. $E$, hoje enfim, penso que poderá ser $0 \%$ quem nunca tenha usado pelo menos um PowerPoint numa aula. E vamos fazendo com velocidades diferentes e também com intensidade[s] diferentes. E acho que isso é bom, é positivo que representa a diversidade, que representa riqueza na experiência formativa dos alunos".

A visão da professora A é voltada para as técnicas de ensino. Segundo sua percepção, o uso de técnicas de ensino, mediadas por dispositivos, no caso o uso do PowerPoint, facilitou a utilização de elementos audiovisuais no ensino de Comunicação Social/Jornalismo na Universidade A. Essa é uma visão comum, pois representa o primeiro impacto possível, que é a inserção de meios nas aulas. É interessante notar a indicação de que houve aderência paulatina à utilização de elementos audiovisuais nas aulas e que aconteceu em tempos e espaços diferenciados dentro do colegiado de professores.

Já para o prof. Dr. B, o impacto nas práticas docentes envolvidas na formação foi mais além, tendo sido "[...] percebido [...] Primeiro, pelo contato que os professores continuam a ter com as 


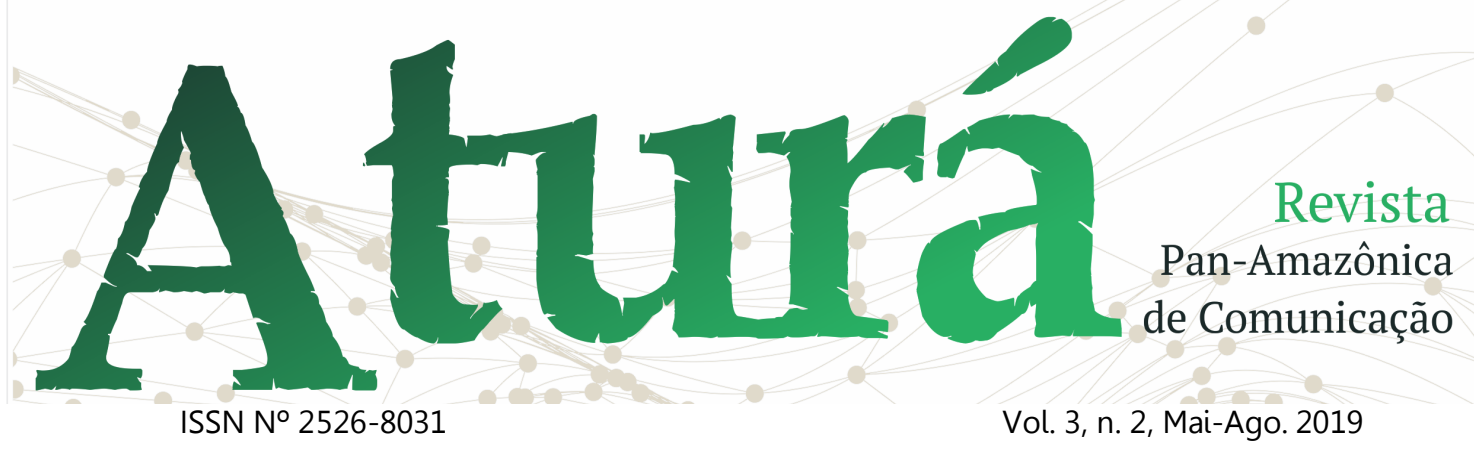

empresas e percebem que as rotinas dentro das empresas estão a ser alteradas. E, portanto, compete à Universidade preparar os estudantes também $\mathrm{p}[\mathrm{a}] \mathrm{ra}$ o mercado de trabalho. Qualquer professor deve saber o que está a acontecer nas empresas de forma a preparar os seus alunos para as empresas. [...] Acontece que historicamente, pelo menos no campo do jornalismo, em Portugal, o ensino sempre andou com passo, e as empresas e os profissionais com passos completamente diferentes. $\mathrm{E}$, durante muito tempo, houve aqui um conflito entre a prática e o ensino. [...] De qualquer das formas, continua a acontecer o mesmo, ou seja, a universidade ainda não está a conseguir puxar pelas empresas neste campo da investigação, e eu tenho visto sempre o digital como uma oportunidade para isto acontecer".

A visão do professor $B$ foi mais além. Seu olhar foi direcionado para a percepção da tênue e complexa linha entre mercado e universidade. Segundo sua percepção, o impacto nas práticas docentes passou pela compreensão dos espaços e dos tempos formativos, ou melhor, pelo descompasso entre o que se ensina em sala de aula e as mudanças que o mercado sofre com as constantes atualizações. Essa é uma realidade existente em praticamente todas as áreas formativas, mas o caminho para a superação desse descompasso é, segundo o a(u)tor, o desenvolvimento do campo "digital". E, dessa forma, o impacto sobre o ensino de Comunicação Social/Jornalismo em Portugal é encarado pelo professor B como "[...] uma oportunidade para isto acontecer".

Avaliando $o$ processo $e$ as repercussões da tecnologia na formação, o prof. Dr. C conclui que "[...] penso que as novas tecnologias permitiram uma visibilidade dos cursos entre si, da produção do que estava a fazer que não houve em outras áreas. E, portanto, aí foi um fortalecimento que constituiu um elemento na afirmação e na consolidação deste campo de pesquisa - [a Comunicação Social/Jornalismo]". De fato, as tecnologias digitais, potencializadas pelas mudanças pósBolonha, permitiram a inclusão de novas demandas ao ensino de Comunicação Social/Jornalismo. Essa visibilidade do conhecimento em Comunicação, propiciada pela assunção das tecnologias digitais e fortalecida pelas demandas de Bolonha - de uma educação ao longo da vida, da partilha e da mobilidade de pessoas e do conhecimento -, permitiu a construção de um espaço coletivo, em que os participantes assumem também processos de autoria.

$$
\text { Para a prof. }{ }^{a} \text { Dr. }^{a} \text { D, da }
$$
Universidade $B$, as mudanças nas práticas docentes são também da própria 


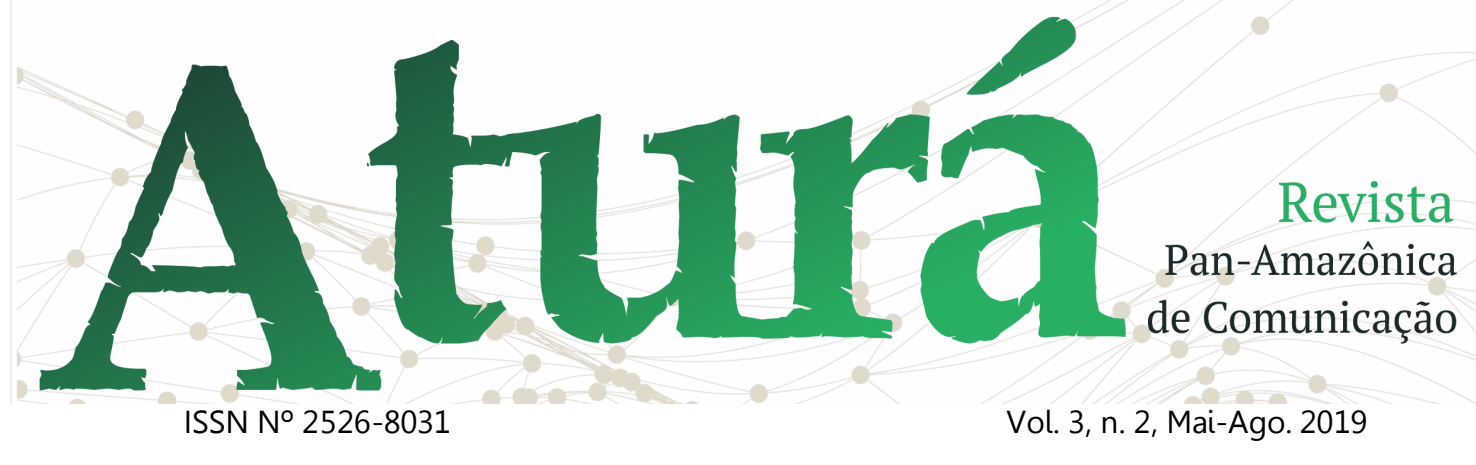

percepção do que se faz em sala de aula. Para Pires, "[...] as transformações eu acho que são radicais e esta é uma questão que me interessa muito particularmente. Como docente, eu tenho me preocupado muito ultimamente. Em primeiro lugar, [...] criou-se esta expectativa à utilização do PowerPoint. [...] o fato de eu planejar a aula com o PowerPoint e depois seguir [o] PowerPoint, pode-se seguir de forma mais sistemática ou menos sistemática e claro que há uma variante. Isto diz que cada vez mais nós plane[j]amos as aulas e programamos as aulas como quem faz um programa de engenharia, como quem programa uma máquina. Portanto, eu acho que, em termos de espontaneidade, há perdas [...]. É claro que tem uns que se sentem mais organizados, menos organizados, uns que planejam mais as aulas, outros que planejam menos as aulas. Enfim, usávamos os apontamentos críticos nas aulas, fazíamos os apontamentos em papel, mas havia mais convite a alguma deriva. $E$ essa deriva às vezes é fundamental para motivar o aluno às histórias [...]. É o imprevisível, é aquilo que vai acontecendo, que não é só ditado por plano. Eu acho que o fato de confundirmos o plane[j]ar a aula com 0 fazer o PowerPoint da aula, de algum modo, concordo com alguma perda de espontaneidade, o acontecer da aula. $\mathrm{O}$ que não quer com isto dizer que não é uma aula plane[j]ada, não é isto. Por outro lado, também me parece que os alunos [...] cada vez mais têm expectativa e até exigem planejamento, eles gosta[m] um pouco. Acho que cada vez mais os alunos têm necessidade da segurança e do plano e daquilo que está ali, cada vez mais os alunos não lidam bem com a deriva".

A fala da a(u)tora é muito rica em termos de percepções. Primeiro, ela expõe aquilo que inicialmente foi destacado pela professora A: o uso de elementos audiovisuais nas aulas. Mas sua visão vai mais além quando aponta a realidade conflituosa entre planejar e programar uma aula. Muitas vezes o docente entende que fazer uma apresentação em PowerPoint é o planejamento de aula, quando na verdade ele está programando o uso de seu tempo em sala de aula com o auxílio de um dispositivo técnico. Essa realidade foi sentida pela a(u)tora entre seus colegas na Universidade B.

Um segundo elemento que surge na fala é a falta de espontaneidade que parece emanar das aulas mediadas pelos elementos audiovisuais, sobretudo o PowerPoint. Em diversos momentos, a $a(u)$ tora expressa sua preocupação com a perda desse elemento formativo, que, em sua percepção, também faz parte da prática docente em Jornalismo e Comunicação Social. 


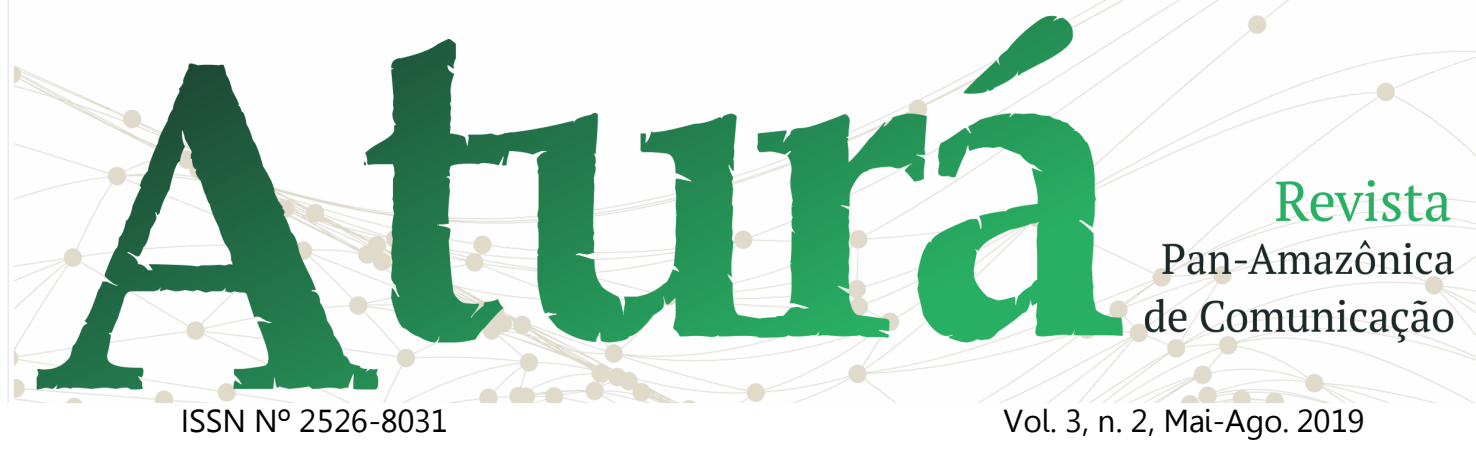

E um terceiro elemento, atrelado aos dois anteriores, é a deriva pedagógica, que pode ser filosófica, sociológica, enfim, depende da área de percepção do docente. Essa deriva, isto é, a capacidade docente de se desviar do 'planejado' com segurança para aprofundar ou trazer outros olhares durante a prática pedagógica é cada vez menos presente nos processos formativos. Segundo a professora C, "[...] os alunos têm necessidade da segurança e do plano e daquilo que está ali", isto é, o nível de programação do acadêmico é bem alto, conforme expresso, ao ponto de "[...] os alunos não lida[rem] bem com a deriva". Esses elementos expostos pela professora $C$ são preocupantes, pois as premissas de Bolonha apontam para alunos com potencial crítico e com visão ampla, com autonomia para encontrarem espaços e outras possibilidades em meio a situações concretas de formação, o que não se corrobora com a indicação da a(u)tora. Dessa forma, as práticas docentes devem caminhar para quebra dessa situação. Isso também perpassa pela qualificação do pessoal docente.

Para o prof. Dr. D, da Universidade $B$, a situação que passa a universidade é de "[...] uma carência de pessoal para permitir uma metodologia de aprendizagem adequada, porque $\mathrm{o}$ uso das tecnologias, que são andaimes de uma construção, não [é] propriamente o objetivo da formação. Esse é desejado, é colhido e é praticado, mas não é com a extensão que nós desejávamos porque, com a [...] crise econômica em geral, as universidades têm uma margem do manobramento reduzido e, nos últimos tempos, cada vez mais reduzida. [...] com a saída de pessoas p[a]ra fora, não há autorização para contratar novos e, pelo contrário, uma exigência aquecida do ponto de vista da oferta formativa ao nível das pós-graduações, dos ciclos de estudos noturnos para novos segmentos da população, que demandam uma formação acadêmica, uma formação avançada. Portanto, as condições concretas para o uso das tecnologias são mais difíceis hoje do que já foram".

Esta é uma realidade complexa e externada por outros a(u)tores em suas percepções: a falta de professores e sua qualificação para a docência. As práticas docentes, em muitos casos, assim como também ocorre no Brasil, são deixadas de lado ou minimizadas pelo excesso de trabalho dentro do espaço universitário. As crescentes demandas dentro do espaço acadêmico têm como resultante a quebra do papel do docente como intelectual de sua área, que, em muitos casos, é visto como um "tarefeiro" com diversas disciplinas e demandas. Daí se infere que as visões dos professores $C$ e $D$ podem ser complementares, isto é, o docente, como tarefeiro e não intelectual 


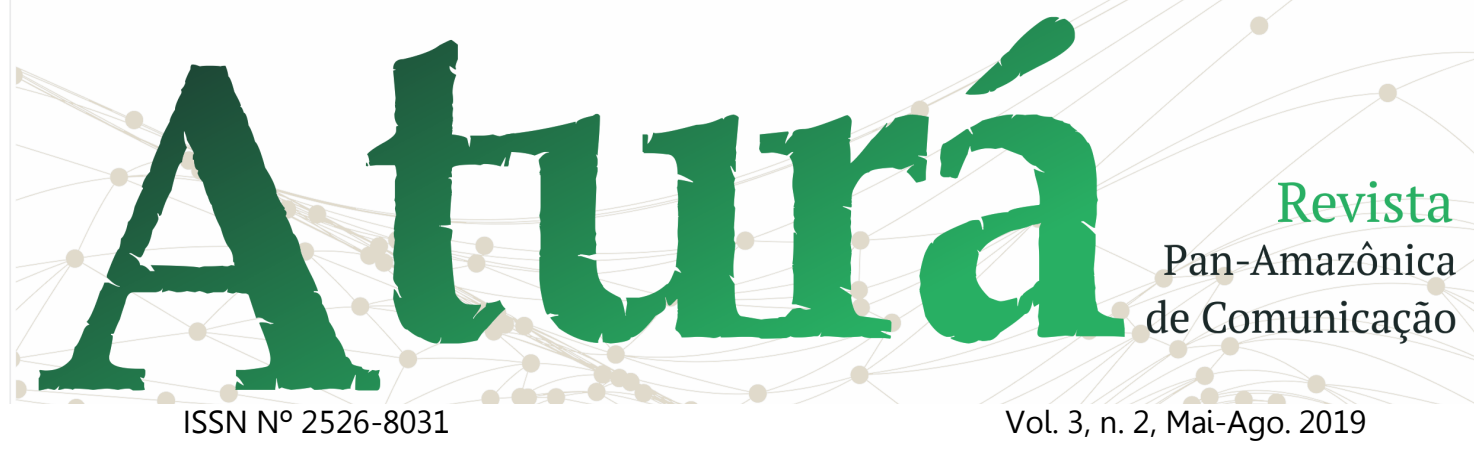

pleno utiliza-se cada vez mais de elementos audiovisuais nas aulas, pois gera um sentimento de garantia de planejamento executado ou, pelo menos, de conteúdo abordado.

Ainda pensando nesse movimento na Universidade $B$, a prof. ${ }^{a}$ Dr. $^{a} \mathrm{E}$ atesta que a mudança na ação docente por conta das tecnologias digitais e por Bolonha exigiu uma maneira diferenciada do pensar docente: "[...] Nós tivemos, nós próprios tivemos que nos converter para pensar de outra maneira e sermos capazes de ensinar dessa maneira, desse ponto de vista e depois do ponto de vista que as transversões das unidades curriculares, que é utilizar ferramentas, como, por exemplo, no e-learning [...] e tem que ser intuitivo para os alunos saberem utiliza[r] essas ferramentas e outros aspectos. No campo de Jornalismo, eu frisaria essa tal lógica multimédia não imperava".

A percepção da a(u)tora é de que houve a necessidade de uma mudança na forma como se concebiam as práticas de ensino. Mas essa mudança necessária não foi desencadeada pela unidade acadêmica, porém pelos próprios docentes, na medida em que se apropriavam das ferramentas tecnológicas. Isso complementa as falas dos professores C e D e agrega a importância da formação desencadeada pela própria unidade acadêmica como parte de suas funções inerentes à manutenção da qualidade dos processos de formação.

Um ponto de vista diferente, mas que reforça o impacto do uso das tecnologias nas práticas docentes, é expresso pelo prof. Dr. F. Para ele, "[...] A nossa universidade [Universidade $\mathrm{C}$ ] tem, esta que é triste, que está muito informatizado e, portanto, de uma forma ou de outra, os professores, por maior ou menos resistência, tiveram que ser adaptados. Há sempre alguém com resistência, nomeadamente as pessoas já com uma certa idade, para quem as novas tecnologias nem sempre são fáceis, muitas vezes são áridas. Nós vemos isso cotidianamente na nossa casa com os nossos pais, muitas vezes não estão habi[li]tados e não estão à vontade com tecnologias que a nós parece[m] relativamente simples [...]. Nosso corpo docente, como instituição, é jovem, quase todos nós fomos pessoas que crescemos com essa tecnologia. Agora não podemos falar de pessoas de 58,60 anos que encaram essas tecnologias numa fase tardia da vida, tardia mais ou menos, umas [se] adaptaram bem, mas outras não se adaptaram tão bem. A universidade acabou por forçar de uma maneira ou de outra a usar as novas ferramentas. Os nossos processos são crescentemente imateriais, temos uma plataforma de ensino que não é apenas 


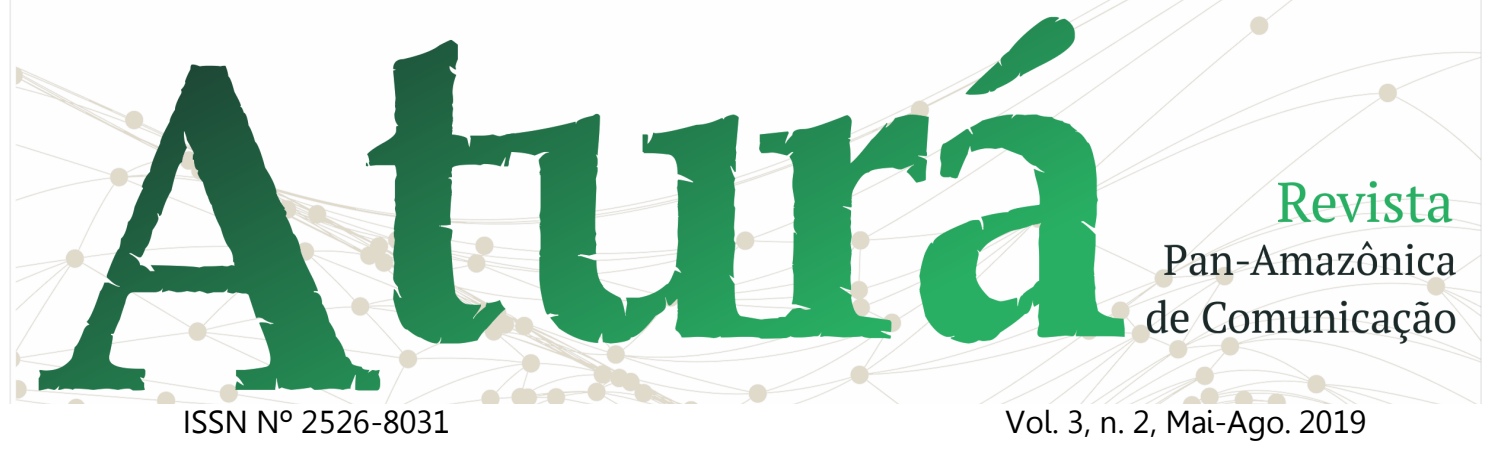

do ensino a distância, é do ensino a distância e presencial, mas que é utilizada significativamente, e não só grande parte dos processos burocrático[s] de avaliação dentro da instituição digitalizados, informatizados e, portanto estão na internet e extranet. Democratizamos muitos, deixamos [de] ter uma relação tão imediata comum [com] o papel. Muitos dos meus colegas tiveram de ter um esforço muito grande para lidar com as novas tecnologias".

$\mathrm{Na}$ fala do a(u)tor, percebe-se o impacto das tecnologias na dinâmica acadêmica na Universidade C. Esta universidade, desde bem cedo informatizada em seus processos acadêmicos, vivenciou resistência de alguns docentes transitarem entre as novas tecnologias. Pela percepção do professor $F$, essa dificuldade era própria da diferença geracional e da absorção desse novo cabedal tecnológico, que ainda é vivenciada por diversos docentes.

Já na visão do prof. Dr. G, a transição das tecnologias nas práticas docentes na Universidade D "[...] foi mais tranquil[a] [...], novas tecnologias com complementos no ensino [...] já estavam entranhadas, digamos assim, nas práticas. Essas práticas já não [são] mais recente[s], é obviamente que os teóricos não têm grande renovação quanto às tecnologias, mas boa parte das cadeiras tem esse componente. E mesmo enfim no decorrer das aulas, as tecnologias são muito aproveitadas para o ensino. A relação foi sempre aparentemente paćfic[a], não se constat[a] grande mudança".

Esse posicionamento do prof. $\mathrm{G}$ é baseado em sua percepção de que o curso de Comunicação Social/Jornalismo da universidade é relativamente novo e que os professores todos eram, de certa forma, imigrantes ou nativos digitais, com amplos conhecimentos na área. Esse domínio de conhecimento nas áreas tecnológicas permitiu aos docentes do curso desenvolver suas atividades, não gerando grandes mudanças.

Diferentemente de Bastos, o Prof. Dr. $H$, também da Universidade $D$, percebeu certo impacto nas práticas, já que "[...] parece-me que alguns docentes mais tradicionais tiveram grande dificuldade de se adaptar, tudo mais até a procedimentos básicos burocráticos de gestão das cadeiras das disciplinas, o próprio relacionamento com os estudantes, [a] utilização básica de ferramentas de e-mail, ferramentas de $e$ learning etc., houve alguma, aí até em gestão de conteúdo extranet, intranet, em partes da universidade, houve alguma dificuldade de adaptação por parte de alguns docentes. E, se calhar, ainda hoje, se nota isso, alguma dificuldade. Um exemplo básico foi a resistência à utilização do PowerPoint em sala de aula como ferramenta de apresentação, como 


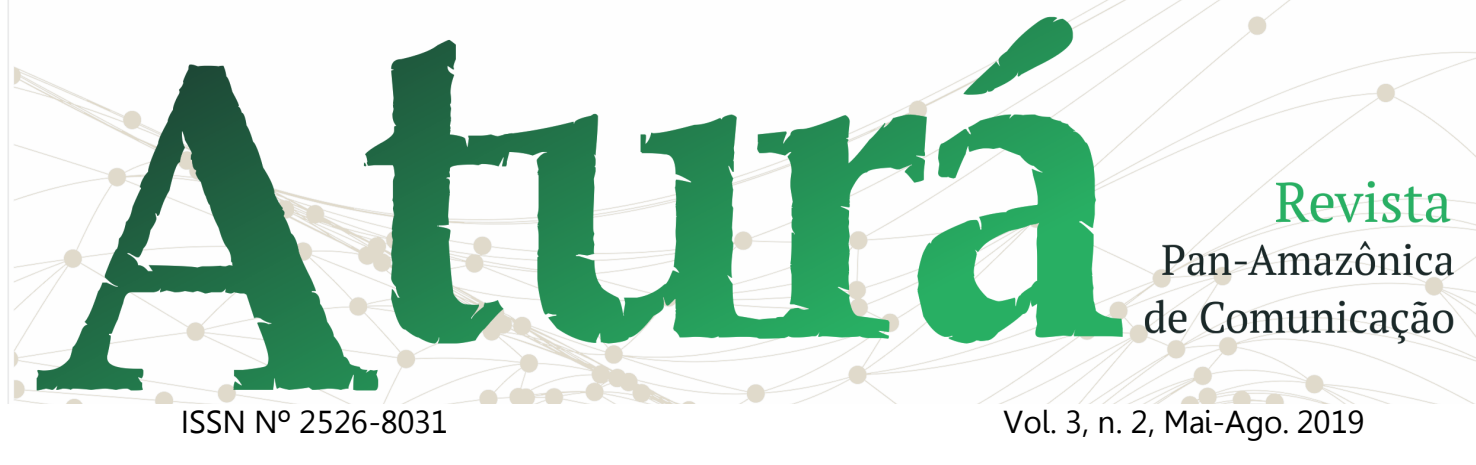

auxiliar do que o professor tem a transmitir. Há uma resistência muito grande por parte de muitos docentes a utilizar, e alguns argumentam com argumentos sólidos".

Posições diferenciadas são comuns quando se pesquisam olhares sobre uma dada realidade. Mas para o professor $\mathrm{H}$, as práticas docentes foram muito impactadas pelas tecnologias. A relação docente-tecnologia em elementos "básicos", como e-mail, ferramentas de $e$ learning e gestão das disciplinas em espaço virtual, não foi simples, ou como apontou Bastos, "pacífic[a]". Essa resistência ao tecnológico na ação docente é sentida pelo professor $\mathrm{H}$, por exemplo, no uso de elementos audiovisuais nas aulas (uso do PowerPoint).

\section{Considerações finais}

No que se refere à percepção das práticas docentes desenvolvidas pelos professores nas instituições pesquisadas, clarifica-se que as tecnologias da comunicação e da informação aplicadas ao ensino passaram, paulatinamente, a fazer parte do lócus pedagógico. Porém a aderência docente foi gradativa, sendo a utilização de elementos audiovisuais nas aulas um processo com "tempos" e "espaços" diferenciados para cada professor.
Os entrevistados destacam que as técnicas de ensino, mediadas por dispositivos, sobretudo o uso do PowerPoint, facilitaram a utilização de elementos audiovisuais no ensino de Comunicação Social/Jornalismo em todas as universidades pesquisadas. Mas registre-se que persistiram as dificuldades, vistas como próprias da diferença geracional e da absorção do tecnológico, gerando resistência entre alguns professores. Agregue-se a isso a difícil relação docente-tecnologia no uso de elementos "básicos" como e-mail, ferramentas de e-learning e gestão das disciplinas em espaços virtuais.

Quanto ao olhar sobre o fazer pedagógico dos professores de Comunicação Social/Jornalismo das universidades estudadas, os entrevistados indicaram percepções importantes. Entre elas, está a realidade conflituosa entre planejar e programar uma aula, em que o uso da tecnologia foi visto como programação do uso do seu tempo em sala de aula e não como elemento de ensino. Também se destacou que a utilização de elementos audiovisuais no ensino, apesar de agregar possibilidades e criar uma sensação de segurança e linearidade do conteúdo ministrado, diminuiu o potencial da deriva pedagógica do professor. Essa possível diminuição da capacidade para aprofundar ou trazer outros olhares 


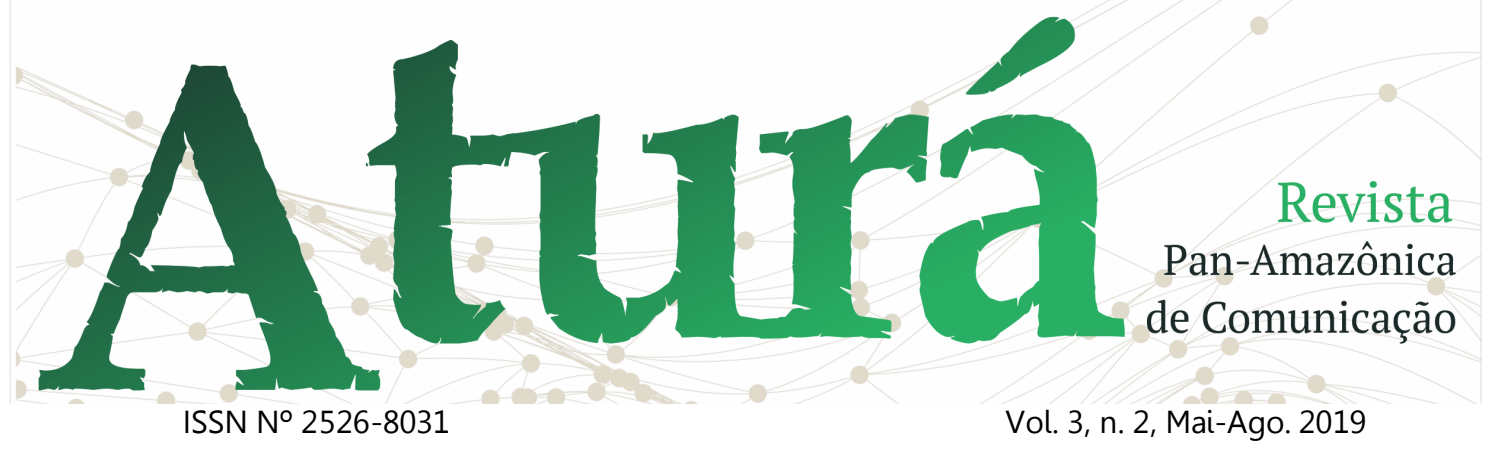

durante a prática pedagógica em Comunicação Social/Jornalismo pode, a longo prazo, interferir no potencial crítico e na autonomia dos acadêmicos, premissas essenciais de Bolonha.

Destaque-se ainda, nas falas dos entrevistados, a percepção de que as práticas docentes têm sido ressignificadas, com impactos na compreensão dos espaços e dos tempos formativos. Esse possível descompasso no binômio tempo-espaço, comum em processos de reestruturação pedagógica, sentido pelos a(u)tores na área de Comunicação Social/Jornalismo, está presente no que se ensina em sala de aula. Algumas percepções permitem extrapolar esse binômio e indicar que essas mudanças interferem nas relações formação inicial e mercado de trabalho.

De qualquer forma, flui, nas falas, o sentido de que as práticas docentes desenvolvidas pelos professores foram, de certa forma, potencializadas pela construção nascedoura de um espaço coletivo, em que os participantes assumiam também processos de autoria. Essa afirmação é embasada na concepção apontada pelos entrevistados de que houve mudanças nas práticas de ensino. Essas mudanças, a priori, não foram desencadeadas pela unidade acadêmica, mas pelos próprios docentes, na medida em que se apropriavam das ferramentas tecnológicas. Agregue-se a isso a percepção de que a falta de professores e de uma possível e necessária qualificação para a docência têm quebrado a visão do papel do docente como intelectual de sua área e não como um "tarefeiro" com diversas disciplinas e demandas.

De uma forma geral, esses aspectos aplicam-se a todas as universidades estudadas, porém nem todos os a(u)tores foram unânimes, nem todos 'sentiram' os processos da mesma forma. A percepção de um deles aponta na direção da normalidade das ações, visto que os professores todos eram, de certa forma, imigrantes ou nativos digitais com amplos conhecimentos na área.

\section{Referências}

ALVES, E.; SILVA, B.; SILVA, R. MAPEAMENTO DOS ESTUDOS SOBRE A FORMAÇÃO DE PROFESSORES NO ÂMBITO DO PROCESSO DE BOLONHA EM PORTUGAL. Revista Observatório, v. 3, n. 6, p. 248-273, 1 out. 2017. DOI: https://doi.org/10.20873/uft.2447-

\subsection{7v3n6p248.}

BATISTA, A.; MACIEL, W. PRISÃO COMO GUETO: a dinâmica de controle e de extermínio de jovens negros pobres. Revista Observatório, v. 4, n. 2, p. 174-200, 1 abr. 2018. DOI: https://doi.org/10.20873/uft.24474266.2018v4n2p174.

MELO, A. ENQUADRAMENTO HISTÓRICO LEGAL DO PROCESSO DE BOLONHA E O 


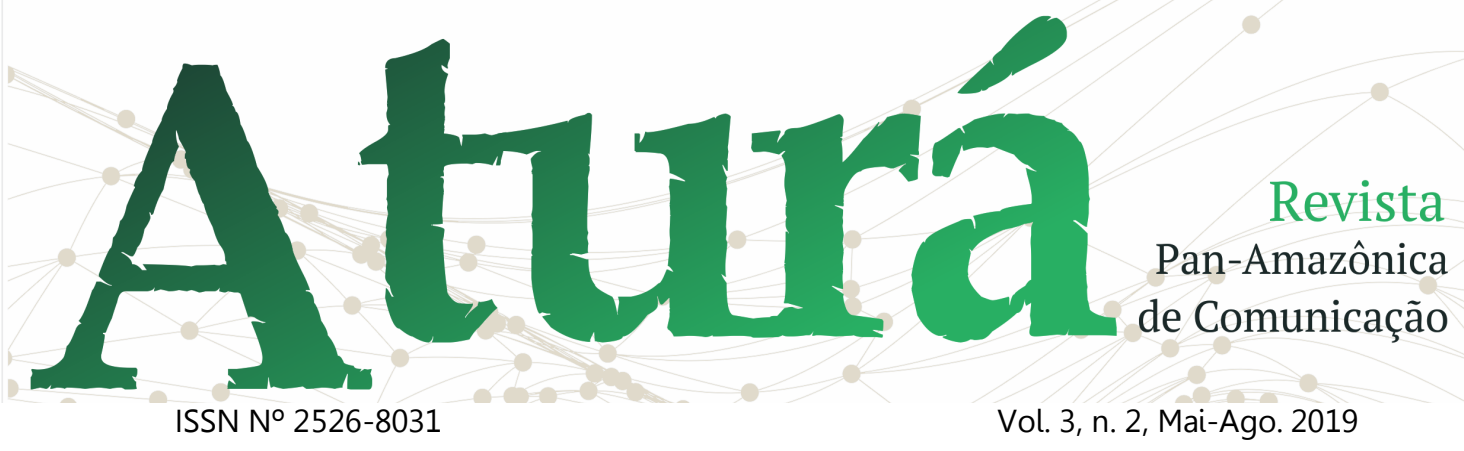

SEU IMPACTO NO SISTEMA DE ENSINO SUPERIOR PORTUGUÊS. Revista Observatório, v. 3, n. 6, p. 75-141, 1 out. 2017.

DOI: https://doi.org/10.20873/uft.24474266.2017v3n6p75. MOIO, I.; ALCOFORADO, L.; VIEIRA, C. A DECLARAÇÃO DE BOLONHA E O REFORÇO DA ABERTURA DO ENSINO SUPERIOR A NOVOS PÚBLICOS: perceções de pessoas adultas que frequentam a Universidade de Coimbra. Revista Observatório, v. 3, n. 6, p. 169-201, 1 out. 2017. DOI: https://doi.org/10.20873/uft.24474266.2017v3n6p169.

MOTA, L.; FERREIRA, A. A FORMAÇÃO DE PROFESSORES EM PORTUGAL NO QUADRO DO ESPAÇO EUROPEU DE ENSINO SUPERIOR. Revista Observatório, v. 3, n. 6, p. 38-74, 1 out. 2017. DOI: https://doi.org/10.20873/uft.24474266.2017v3n6p38.

NUNES, S.; PORTO JUNIOR, F. G. R.; MORAES, N. CONHECIMENTO E ORGANIZAÇÃO: indicativos pós-Bolonha de uma sociedade em construção. Revista Observatório, v. 3, n. 6, p. 338-353, 1 out. 2017.

DOI: https://doi.org/10.20873/uft.24474266.2017v3n6p338.

PÔRTO JUNIOR, F. G. R. Entre Comunicação e Educação: o Processo de Bolonha e as ações formativas em cursos de Comunicação Social / Jornalismo em
Portugal. 2012. 614 f. Tese (Doutorado em Comunicação e Cultura Contemporâneas) Faculdade de Comunicação, Universidade Federal da Bahia, 2012. Disponível em <http// www.repositorio.ufba.br:8080 >. Acesso em 09 nov. 2019.

PORTO JUNIOR, F. G. R.; MORAES, N. FORMANDO PESQUISADORES PÓSBOLONHA EM PORTUGAL: relações entre a formação de graduação e o campo da pesquisa/investigação. Revista

Observatório, v. 3, n. 6, p. 202-228, 1 out. 2017.

DOI: https://doi.org/10.20873/uft.24474266.2017v3n6p202.

PORTO JUNIOR, Francisco Gilson Rebouças. Sobre os processos formativos, Bolonha e o curso de Comunicação Social/Jornalismo: consolidando-se posições nas políticas educacionais. Revista Eletrônica Mutações, [S.l.], v. 6, n. 10, p. 13-24, mar. 2015. ISSN 2178-7018. Disponível em: $<$ http://www.periodicos.ufam.edu.br/rele m/article/view/799 >. Acesso em: $05 \mathrm{dec}$. 2019.

PINHO, M. UNIVERSIDADE E CRISE INSTITUCIONAL: perspectivas de uma formação humana. Revista Observatório, v. 3, n. 6, p. 274-315, 1 out. 2017. DOI: https://doi.org/10.20873/uft.24474266.2017v3n6p274.

REIS, E. O ENSINO SUPERIOR EM CABO VERDE E OS DESAFIOS DO PROCESSO DE 


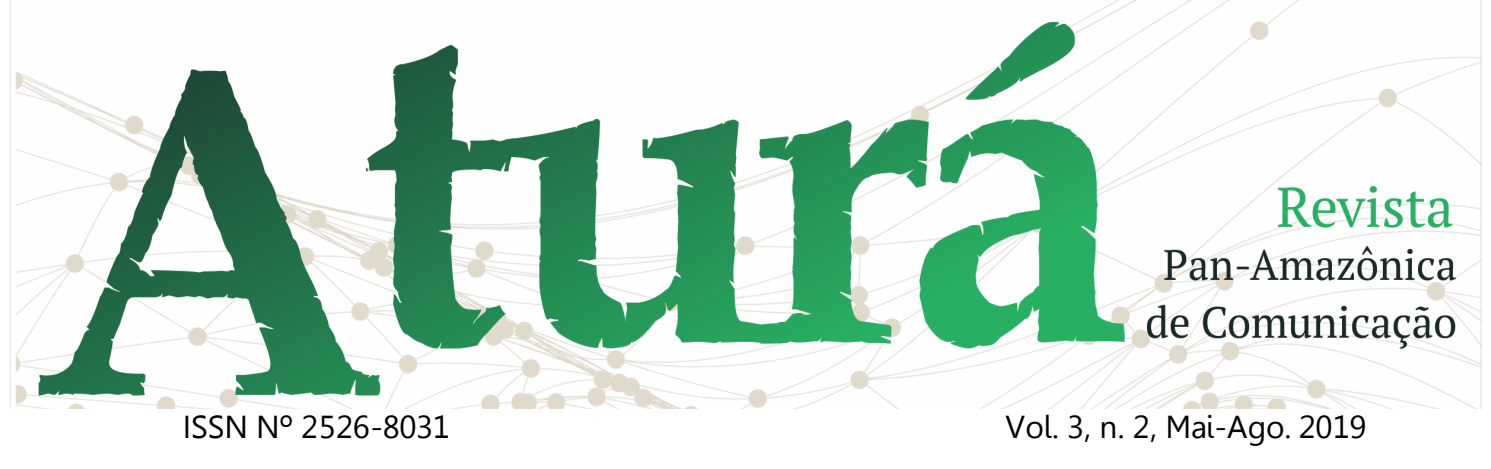

BOLONHA. Revista Observatório, v. 3, n. 6, p. 142-168, 1 out. 2017. DOI: $\underline{\text { https://doi.org/10.20873/uft.2447- }}$

4266.2017v3n6p142.

TEIXEIRA, P. O. O ensino de jornalismo em Portugal uma história e análise dos planos curriculares. Porto, 20092010.Orientador: Prof. Dr. Jorge Pedro Sousa. Dissertação (mestrado). Universidade Fernando Pessoa. $165 \mathrm{f}$. Disponível em < http://bdigital.ufp.pt/bitstream/10284/16 81/2/DM_19061.pdf>. Acesso 04 set. 2017.

TEIXEIRA, I.; DA SILVA, V.; MARTINS, J. A CONVERGÊNCIA MIDIÁTICA E AS TECNOLOGIAS MÓVEIS PÓS-BOLONHA: NOVAS PRÁTICAS SOCIAIS. Revista Observatório, v. 3, n. 6, p. 229-247, 1 out. 2017.

DOI: $\underline{\text { https://doi.org/10.20873/uft.2447- }}$ 4266.2017v3n6p229. 